\title{
Influência da microestrutura na resistência ao desgaste microabrasivo de ligas de F-Cr-C e Fe-Cr-C-Nb
}

\section{Influence of microstructure on micro-abrasive wear resistance of alloys $\mathrm{Fe}-\mathrm{Cr}-\mathrm{C}$ and $\mathrm{Fe}-\mathrm{Cr}-\mathrm{C}-\mathrm{Nb}$}

Tatiane Gabi de Oliveira ${ }^{1}$, Adilson Rodrigues da Costa ${ }^{1}$

\author{
${ }^{1}$ Laboratório de Engenharia de Superfície e Técnicas Afins - Escola de Minas/UFOP, CEP: 35400-000, Ouro Preto, \\ Minas Gerais, Brasil. \\ e-mail: tatygbo@hotmail.com, adilson@em.ufop.br
}

\section{RESUMO}

Neste trabalho é feita uma avaliação da influência do teor de cromo e da combinação do cromo e nióbio em ligas de revestimento duro do tipo $\mathrm{Fe}-\mathrm{Cr}-\mathrm{C}$, na microestrutura e propriedades que envolvam a resistência ao desgaste microabrasivo. Vários estudos têm sido realizados em busca de informações conclusivas sobre este sistema em condições de desgaste, devido às distintas fases e propriedades apresentadas por estas ligas. As ligas de $\mathrm{Fe}-\mathrm{Cr}-\mathrm{C}$ associam fases duras (carbonetos), com uma matriz metálica, o que lhes proporciona elevada dureza e resistência mecânica.

Para realização dos experimentos, foram utilizadas as ligas de $\mathrm{Fe}-\mathrm{Cr}-\mathrm{C}$ comerciais, em forma de consumíveis (eletrodos e arame) e aplicadas em aço carbono ASTM A36 por meio de processos de soldagem SMAW e GMAW, respectivamente, como revestimentos. Neste caso, foram utilizados dois eletrodos com adição de 25 e $45 \%$ em peso de cromo e um arame com 20 e $5 \%$ em peso de cromo e nióbio, respectivamente.

O ensaio de desgaste por microabrasão foi realizado utilizando o teste por esfera rotativa fixa e, como abrasivo, uma suspensão de diamante de granulação $3 \mu \mathrm{m}$. Para o qual, foram utilizados 4 corpos de prova referentes à cada liga. Para determinar o coeficiente de desgaste foi obtida a perda média de volume de material, em intervalos de tempo de ensaio pré-estabelecidos, relacionando o resultado com a distância de deslizamento.

Ao analisar os resultados obtidos, verificou-se que a liga que apresentou combinação de cromo e nióbio em sua composição exibiu melhores resultados de resistência ao desgaste, embora apresentasse menores valores de dureza e percentual de carbonetos em relação às outras duas ligas. Tal fato evidencia a possibilidade de se utilizar tais ligas em aplicações que requerem alto desempenho em relação à resistência ao desgaste.

Palavras-chave: Nióbio, Cromo, Resistência ao desgaste, Microabrasão, Esfera rotativa.

\section{ABSTRACT}

This paper presents an evaluation of the influence of chromium content and the blend of chromium and niobium in $\mathrm{Fe}-\mathrm{Cr}-\mathrm{C}$ hardfacing alloys on the microstructure and properties that involve microabrasive wear resistance. Various studies have been carried out searching for conclusive information on this system under wear conditions, due to the different phases and properties presented by these alloys. These alloys associate carbides with a metallic matrix giving them high hardness and mechanical resistance.

For the realization of the experiments, commercial $\mathrm{Fe}-\mathrm{Cr}-\mathrm{C}$ alloys were obtained in the form of consumables (electrodes and wire) and applied as coatings on ASTM A36 carbon steel by means of SMAW and GMAW welding processes, respectively. In this case, two electrodes with addition of 25 and 45 percent by weight of chromium and a wire with 20 and 5 percent by weight of chromium and niobium, respectively, were used.

The microabrasion wear test was performed using the fixed rotating ball method and, as an abrasive, a diamond suspension of $3 \mu \mathrm{m}$ granulation. For this, four test specimens were used for each alloy. In order to calculate the wear coefficient, the average loss in volume was determined at pre-established time intervals, relating the result to the sliding distance.

When analyzing the obtained results, it was verified that the alloy that presented the combination of chromi- 
um and niobium in its composition had better wear resistance results, although it showed lower values of hardness and volume fraction of carbide in comparison to the other two alloys. Such result evidences the possibility of using such alloy in applications that require high performance in relation to wear resistance.

Keywords: Niobium, Chromium, Wear resistance, Microabrasion, Rotating ball.

\section{INTRODUÇÃO}

Os equipamentos e materiais utilizados em setores industriais, tais como a mineração, sucroenergia e siderurgia, são expostos ao desgaste, diante das condições de trabalho que lhes são impostas. Por isso, há necessidade desenvolver tecnologias visando proteção das superfícies, de forma a diminuir o desgaste, o que implica na diminuição das paradas constantes para manutenção, que é um dos fatores de queda de produção [1].

Uma alternativa para tentar sanar a depreciação de capital, gerada pela deterioração dos equipamentos, tem sido a utilização de revestimentos, em especial, os aplicados por meio de processos de soldagem, selecionados em função da aplicação, objetivando melhores resultados diante das solicitações mecânicas a que estes componentes são submetidos. Portanto, há interesse, por parte das empresas, por materiais e tecnologias "antidesgaste", com a pretensão de estender a vida útil de peças e equipamentos [2].

Os revestimentos são produzidos, em sua grande maioria, baseados em ligas especiais e aplicados utilizando processos de soldagem. Podem ser obtidos por meio de cordões de solda ou placas revestidas, procedimentos bastante difundidos, principalmente, devido ao custo [2].

A escolha dos processos de soldagem, utilizados pelos setores industriais para a aplicação dos revestimentos, é feita de forma que se obtenha a melhor taxa de deposição combinada à mínima diluição. Desta forma é possível obter um maior rendimento sem que ocorram mudanças na composição química do revestimento, fator que pode causar perdas nas propriedades pretendidas. [3]

Os processos de soldagem por eletrodo revestido e por arame (MIG/MAG), também conhecidos como SMAW (Shielded Metal Arc Welding) e GMAW (gas metal arc welding), respectivamente, são os mais utilizados para aplicação de tais revestimentos pelo meio industrial atualmente. Isto devido ao controle de variáveis apresentado pelo processo GMAW, o que permite obter melhores resultados, bem como as vantagens de menor custo de processo e simplicidade de procedimento apresentada pelo processo SMAW.[4]

As ligas de revestimento duro, do tipo $\mathrm{Fe}-\mathrm{Cr}-\mathrm{C}$, com ou sem adição de outros elementos de ligas, têm sido muito utilizadas, devido a grande variedade de microconstituíntes aliado a uma matriz metálica, conferindo-lhes dureza e resistência mecânica satisfatória à aplicação [5].

Estas ligas de $\mathrm{Fe}-\mathrm{Cr}-\mathrm{C}$ podem apresentar em sua composição carbonetos distintos, tanto em composição quanto em propriedades. Geralmente são formadas fases do tipo $\mathrm{MC}, \mathrm{M}_{6} \mathrm{C}, \mathrm{M}_{7} \mathrm{C}_{3}, \mathrm{M}_{23} \mathrm{C}_{6}$ e $\mathrm{Cr}_{2} \mathrm{C}_{3}$, no qual $\mathrm{M}$ correspondem aos átomos metálicos. As características destas fases dependem da composição química, bem como processo de solidificação e resfriamento após o processo de soldagem [6].

BENS [7] destaca a importância de parâmetros microestruturais no desgaste abrasivo dos materiais, sabendo que características dos carbonetos, tais como tamanho, distribuição na matriz, morfologia e fração volumétrica, afetam a taxa de desgaste.

Além disso, a presença e a combinação entre os elementos de liga, como o nióbio e cromo, podem alterar as propriedades químicas e mecânicas destas fases, pois de acordo com a variação do teor destes elementos, o percentual de carbonetos se altera durante o processo de solidificação, conferindo-lhes melhores propriedades de resistência ao desgaste [8]. De acordo com KIRCHGABNER et al. [2], CORRÊA [8] e LIMA [9], a presença de nióbio em ligas de $\mathrm{Fe}-\mathrm{Cr}-\mathrm{C}$, tende a formar carbonetos do tipo $\mathrm{NbC}$, o que lhes proporcionam melhores resultados de resistência ao desgaste.

Estudos da influência dos teores de cromo e nióbio sobre a resistência à abrasão de ligas de $\mathrm{Fe}-\mathrm{Cr}-\mathrm{C}$, são muito difundidos, porém não há ainda informações suficientes para comprovar o real desempenho diante dos processos abrasivos. [1].

A presença de fases duras impõe limitações quanto às propriedades mecânicas das ligas, pois em muitos casos exibem morfologia grosseira, tornando os revestimentos frágeis, restringindo a resistência ao desgaste [10].

O principal objetivo do presente estudo é entender a influência da microestrutura de revestimentos a base de $\mathrm{Fe}-\mathrm{Cr}-\mathrm{C}$ e Fe-Cr-C-Nb no comportamento tribológico. Neste trabalho procuramos analisar as influências do teor de cromo e nióbio em ligas de $\mathrm{Fe}-\mathrm{Cr}-\mathrm{C}$, sobre a microestrutura e a resistência ao desgaste. Para este fim, foram obtidas as ligas em forma de consumíveis (eletrodos e arame) e aplicados em aço carbono ASTM A36 por meio de processo de soldagem SMAW e GMAW, respectivamente, como revestimentos. 
Para analisar o desempenho dos revestimentos em relação ao desgaste, foi utilizado o ensaio de microabrasão por esfera rotativa fixa, que consiste em uma esfera atuando contra a superfície do corpo de prova na presença de uma suspensão abrasiva [11]. Este equipamento é recomendado pela norma ISO 26424-2008 [12] e consiste basicamente em produzir desgaste a partir da remoção de material produzindo uma cratera.

\section{MATERIAIS E MÉTODOS}

Para confecção dos corpos de prova utilizou-se como substrato placas do aço estrutural ASTM A-36 de dimensões $150 \mathrm{~mm}$ x $50 \mathrm{~mm}$ x 11,7 mm, e para fins de revestimento foram utilizados três consumíveis comerciais do tipo Fe-Cr-C, sendo dois eletrodos revestidos (ligas A e B) e um arame com adição de nióbio (liga C). As composições químicas e referências estão descritas na Tabela 1.

Tabela 1: Composição química dos materiais utilizados (\% em massa).

\begin{tabular}{l|l|l|l|l|l|l|l|l|l}
\hline MATERIAIS & REFERÊNCIA & C & Mn & P & S & Si & Cr & Nb & Fe \\
\hline ASTM A36 & Substrato & 0,25 & $0,80-1,20$ & 0,04 & 0,05 & - & - & - & Restante \\
\hline Fe-Cr-C & Liga A & 5,30 & 0,85 & - & - & 1,25 & 45,00 & - & Restante \\
\hline Fe-Cr-C & Liga B & 4,10 & 0,40 & - & - & 1,42 & 25,00 & - & Restante \\
\hline Fe-Cr-C-Nb & Liga C & 5,00 & 2,00 & - & - & 1,00 & 20,00 & 5,00 & Restante \\
\hline
\end{tabular}

A aplicação do revestimento ao substrato foi realizada por meio de processo de soldagem. Em cada amostra foram depositados quatro cordões de solda de $5 \mathrm{~mm}$ de altura e $150 \mathrm{~mm}$ de comprimento, em camada única, obtendo-se uma peça com $16,7 \mathrm{~mm}$ de espessura total, realizando-se sobreposição de $30 \%$ da largura de cada cordão, para obtenção de uma superfície mais uniforme. Os revestimentos A e B foram aplicados por meio do processo de soldagem por eletrodo revestido (SMAW), enquanto $\mathrm{C}$ foi aplicado por soldagem MIG (GMAW), utilizando parâmetros testados por outros autores $[9,13]$, conforme Tabela 2. Para todas as deposições a temperatura de pré-aquecimento e interpasse foi de $100{ }^{\circ} \mathrm{C}$, a fim de reduzir os efeitos do calor fornecido entre passes e prevenir nucleação de trincas nas amostras.

Tabela 2: Parâmetros operacionais para o processo de soldagem conforme $[9,13]$.

\begin{tabular}{l|l|l|l|l|l|l|l|l}
\hline REVEST. & PASSE & $\begin{array}{c}\text { PROCESSO } \\
\text { DE SOLD. }\end{array}$ & $\begin{array}{c}\text { DIÂMETRO } \\
\mathbf{m m}\end{array}$ & $\begin{array}{c}\text { CORRENTE / } \\
\text { POLARIDADE }\end{array}$ & $\begin{array}{c}\text { INT. DE } \\
\text { CORRENTE } \\
\mathbf{A}\end{array}$ & $\begin{array}{c}\text { TENSÃO } \\
\mathbf{V}\end{array}$ & $\begin{array}{c}\text { VELOCIDADE } \\
\mathbf{c m} / \mathbf{m i n}\end{array}$ & $\begin{array}{c}\text { VELOCIDADE } \\
\text { DE ALIM. } \\
\mathbf{m m} / \mathbf{m i n}\end{array}$ \\
\hline Liga A & Revest. & SMAW & 3,25 & CC+ & 170 & 40 & $14 \sim 16$ & - \\
\hline Liga B & Revest. & SMAW & 3,25 & CC+ & 170 & 40 & $14 \sim 16$ & - \\
\hline Liga C & Revest. & GMAW & 1,6 & CC+ & 290 & 28 & $15 \sim 16$ & 8 \\
\hline
\end{tabular}

Para cada tipo de revestimento produzido, foram retirados cinco corpos de prova da região central das amostras, com dimensões 25,0 $\mathrm{mm}$ x 25,0 $\mathrm{mm}$ x 16,7 $\mathrm{mm}$ para realização dos ensaios. Destes foram separados quatro corpos de prova para realização dos ensaios de microabrasão e dureza Rockwell C e um corpo de prova de cada para os ensaios de microdureza Vickers e metalografia. As demais partes, que representam o início e fim dos cordões de solda, foram descartadas, de forma a eliminar os efeitos transitórios do início e fim do processo de soldagem.

Para a realização dos ensaios microabrasivo e de dureza Rockwell C, os corpos de prova foram submetidos ao processo de lixamento utilizando lixas de granas 60, 120, 180, 400 e 600 mesh, de forma a obter uma superfície plana e uniforme. E os corpos de prova separados para metalografia e microdureza Vickers, foram inicialmente embutidos, utilizando resina de poliéster, lixados utilizando lixas de granas 180, 240, 320, 400, 600, 800, 1000 e 1200 mesh, e por fim submetidos ao processo de polimento utilizando alumina $1 \mu \mathrm{m}$, pasta diamantada de granulometrias $1 \mu \mathrm{m}$ e $0,25 \mu \mathrm{m}$, nesta sequência. 
Para verificar a dureza dos revestimentos, foi realizado um perfil de dureza utilizando o ensaio de microdureza Vickers (HV). A análise constituiu em 26 medições na secção transversal de cada amostra em espaçamentos de $0,4 \mathrm{~mm}$ na direção revestimento/substrato. Esta série foi repetida por três vezes, totalizando 78 medições em cada uma das ligas estudadas. A carga aplicada foi de $1 \mathrm{kgf}$ em um tempo de impressão de 10 segundos. A análise de microdureza foi realizada em um microdurômetro com indentador Vickers da marca PANTEC. Para obtenção da dureza superficial realizou-se cinco medições de dureza Rockwell C em três corpos de prova de cada, totalizando 15 medições em acordo com a norma ABNT-NBR 6671-198. Para este procedimento utilizou-se um equipamento WOLPERT DIATESTOR 2-RC, sendo a pré-carga de 10kgf e carga de $150 \mathrm{kgf}$.

Os corpos de prova separados para caracterização microestrutural, após serem lixados, foram atacados com reagente Murakami a $60^{\circ} \mathrm{C}$ por um tempo de 20 segundos, de forma a destacar os carbonetos de cromo e nióbio presentes nos revestimentos. Após isto, foi realizada a análise por meio da microscopia óptica (MO) com aumentos de 500 e 1000 vezes. Para este fim, utilizou-se um microscópio ótico trinocular, da marca LEICA DM2700M, com câmera de captura de imagens. E de forma a comprovar a presença dos constituintes das fases detectadas pela microscopia óptica, foram realizadas análises por microscopia eletrônica de varredura (MEV) equipado com sistema de energia dispersiva (EDS), modelo TESCAN do Laboratório Nanolab.

O calculo do percentual de carbonetos foi realizado com o auxílio da ferramenta digital "Image J". Tal procedimento foi possível devido ao ataque seletivo dos carbonetos obtido por meio do reagente Murakami a $60^{\circ} \mathrm{C}$, pois este ataque permite um melhor destaque dos carbonetos de cromo e nióbio presentes em relação à matriz, viabilizando realizar o cálculo da área superficial ocupada em relação à área total [9]. O procedimento iniciou-se convertendo cada uma das imagens originais analisadas em uma escala de cinza (8 - bits), e a partir do histograma de máximo e mínimo dos tons de cinza foi possível distinguir os carbonetos em relação à matriz. E por meio da segmentação da área demarcada o software, Image J, contabilizou a área selecionada, possibilitado o calculo do percentual de carbonetos presentes na microestrutura. Este procedimento foi realizado em 10 imagens referentes a cada liga estudada.

\subsection{Ensaios de desgaste microabrasivo}

Os ensaios de microabrasão foram realizados com um equipamento de micro desgaste por esfera rotativa fixa, desenvolvido pelo LESTA (Laboratório de Engenharia de superfícies e técnicas afins). Neste equipamento o controle da força normal é feito a partir de uma célula de carga, FSR-406, fabricado pela Interlink Eletronics e a leitura do sensor é feita por uma porta analógica de um Arduino, que permite a interface entre a aplicação principal do MATLAB e os periféricos eletrônicos. Tal controle pode ser realizado em um sistema supervisório, que em tempo real, permite visualizar os parâmetros do ensaio.

Para realização do experimento foi utilizada uma esfera de aço AISI 52100 de diâmetro 25,4 mm, a qual é fixa em um eixo rotacional, que se movimenta com o auxílio de um motor. Como abrasivo, utilizou-se uma suspensão de diamante, com tamanho médio de partícula de $3 \mu \mathrm{m}$, composta por $35 \%$ de pasta diamantada e $65 \%$ de água destilada. Os demais parâmetros de teste utilizados estão apresentados na Tabela 3.

Tabela 3: Parâmetros pré-estabelecidos para os ensaios de microabrasão.

\begin{tabular}{l|l|l|l|l|l|l|l}
\hline TEMPO DE ENSAIO $(\mathrm{s})$ & 900 & 1200 & 1800 & 3600 & 7200 & 10800 & 14400 \\
\hline DISTÂNCIA DE DESLIZAMENTO $(\mathrm{m})$ & 163,43 & 217,90 & 326,85 & 653,70 & 1307,41 & 1961,11 & 2604,56 \\
\hline FORÇA NORMAL $(\mathbf{N})$ & \multicolumn{7}{c}{5,2} \\
\hline ROTAÇÃO DA ESFERA (rpm) & \multicolumn{7}{c}{136} \\
\hline GOTEJAMENTO DO ABRASIVO $($ gota/s) & \multicolumn{7}{c}{0,5} \\
\hline TEMPO DE AMOSTRAGEM (s) & \multicolumn{7}{|c}{4} \\
\hline NÚMERO DE REPETIÇÕES & \multicolumn{7}{|c}{4} \\
\hline
\end{tabular}

Para o estudo do desgaste microabrasivo, inicialmente foi quantificada a perda de volume dos corpos de prova a partir da evolução do diâmetro das crateras formadas em função da distância de deslizamento. Para esta análise, utilizou-se a distância de $651 \mathrm{~m}$, ou seja, 60 minutos de ensaio, tempo necessário para que as três ligas apresentassem um coeficiente de desgaste constante e, portanto considera-se que o regime permanente de desgaste tenha sido atingido [20]. 
As medidas dos diâmetros das crateras formadas foram realizadas a partir de imagens da calota, obtidas com o auxílio do microscópio eletrônico de varredura (MEV) com um aumento de 70x, e para obter informações sobre os mecanismos de desgaste presente foram obtidas imagens com aumento de 2000x. Após isto foi calculado o volume desgastado em cada uma das ligas estudadas, por meio da Equação 1, e calculouse os coeficientes de desgaste, por meio da Equação 2. Desta forma foi possível verificar a severidade do desgaste, bem como se o regime permanente de desgaste foi atingido nas ligas estudadas [21].

$$
\begin{aligned}
& \mathrm{V}=\frac{\pi \cdot d^{4}}{64 . R} \\
& k=\frac{V}{S . N}
\end{aligned}
$$

onde:

- V é o volume de desgaste em $\mathrm{mm}^{3}$;

- d é o diâmetro da calota em mm;

- R é o raio da esfera;

- k é o coeficiente de desgaste (adimensional);

- S é a distância de deslizamento em mm;

- $\quad \mathrm{N}$ é a força normal em Newton (N) aplicada à superfície;

\section{RESULTADOS E DISCUSSÃO}

Serão apresentados resultados referentes à microdureza Vickers (HV), dureza Rockwell C (HRC), microestrutura, além do volume desgastado dos revestimentos estudados.

\subsection{Durezas dos Revestimentos}

Os gráficos da Figura 1(a), (b) e (c) apresentam os resultados de microdureza Vickers e seus respectivos desvios padrões, encontrados para os revestimentos produzidos com as ligas A, B e C, nesta ordem. A Figura 1(d) mostra a comparação dos resultados para as três ligas.

A microdureza Vickers (HV) dos revestimentos foi maior em relação ao substrato, especialmente para o revestimento $\mathrm{A}, \mathrm{Fe}-\mathrm{Cr}-\mathrm{C}(45 \% \mathrm{Cr})$. As oscilações observadas no valor da dureza $\mathrm{HV}$ podem ser resultado de regiões com maior e menor concentração de carbonetos, o que condiz com as afirmativas de BUCHELY [4], de que regiões que apresentam alto volume de carbonetos, consequentemente, exibem maior resistência à penetração e ao corte.

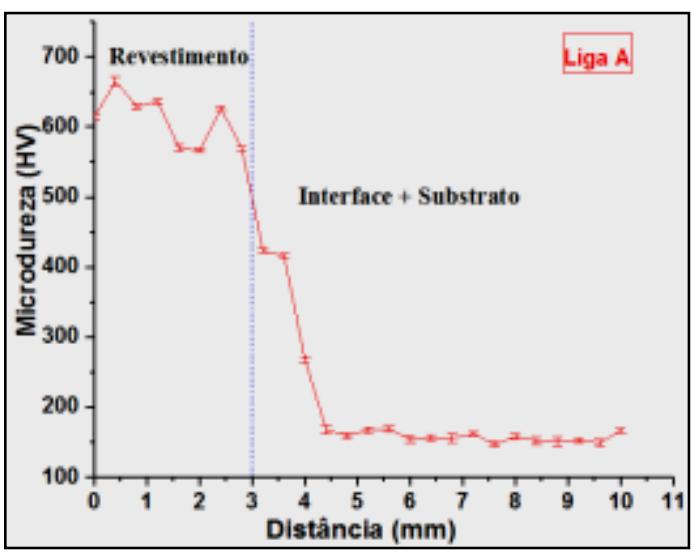

(a)

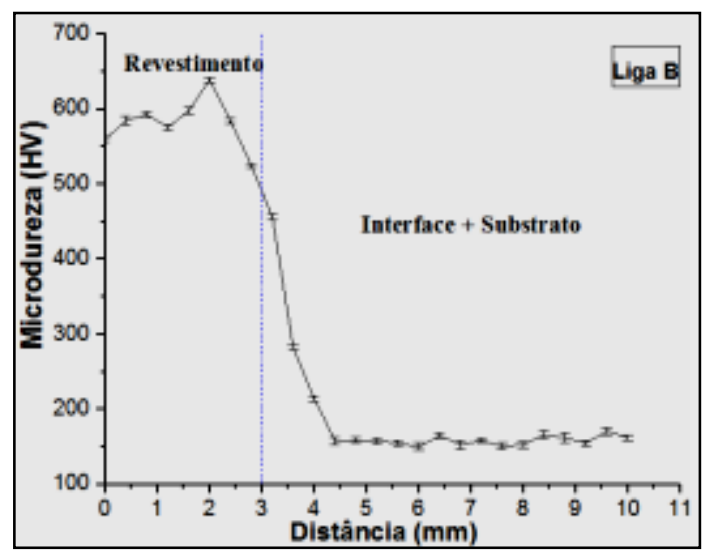

(b) 


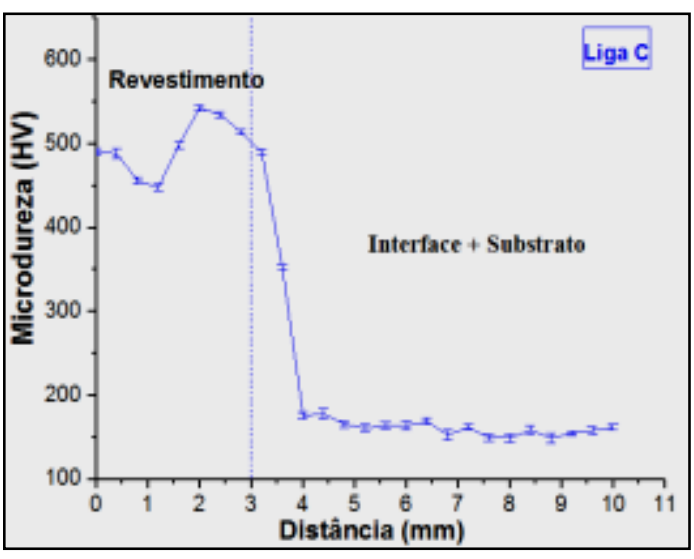

(c)

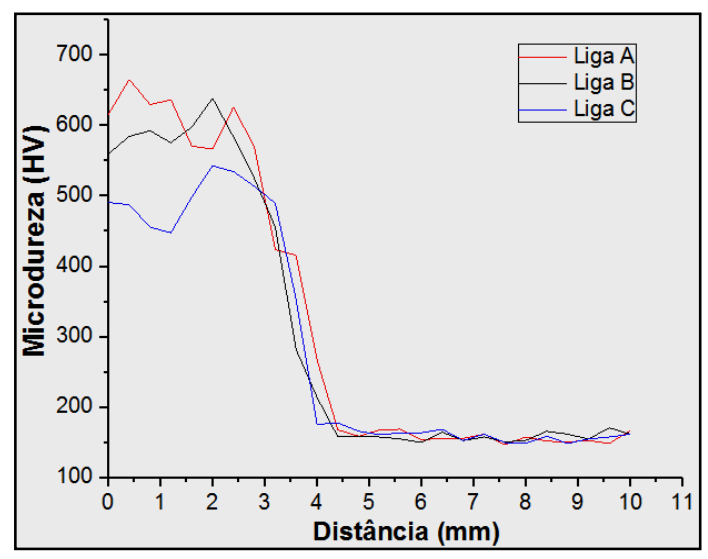

(d)

Figura 1: Medidas da microdureza dos revestimentos e seus respectivos desvios padrões. a) liga A; b) liga B; c) liga C e; d) comparação dos revestimentos.

As médias dos valores obtidos para dureza Rockwell C (HRC), com os respectivos desvios padrões são apresentadas no gráfico da Figura 2, na qual o revestimento que apresentou maior dureza foi o obtido a partir da liga A, Fe-Cr-C (45\%Cr).

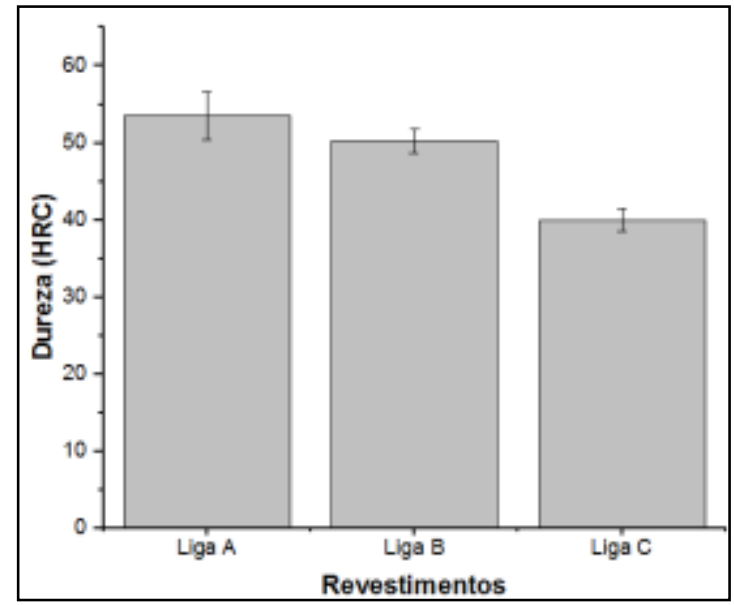

Figura 2: Resultado de dureza (HRC) dos revestimentos obtidos a partir das ligas A, B e C.

\subsection{Análises Microestrutural}

Os três tipos de revestimentos estudados, apresentaram carbonetos do tipo $\mathrm{M}_{7} \mathrm{C}_{3}$ com particularidades características de cada morfologia. Foram encontrados as forma mais grosseira na Liga A e B, nesta ultima os precipitados se formaram em colônias e com um grande espaçamento entre si. Os carbonetos de nióbio ( $\mathrm{NbC})$, presentes em C, apresentaram morfologia do tipo "escrita chinesa", em que os mesmo se apresentam de formas alongadas, dispostos de maneira intercalada aos carbonetos de cromo presentes.

As Figuras 3, 4 e 5, representam as microestruturas obtidas por meio da microscopia óptica, com aumento de 500 e 1000 vezes, utilizando o reagente Murakami à $60^{\circ} \mathrm{C}$ por 20 segundos.

Pode-se observar na Figura 3, que a microestrutura apresentada pela liga A, Fe-Cr-C (45\%Cr), é constituída por carbonetos de cromo, além do constituinte eutético formado por carbonetos de cromo e austenita, semelhante ao encontrado nos trabalhos de BUCHANAN et al. [5], LIMA [9] e WU [14]. Pressupõe-se que durante o processo de solidificação o líquido transformou-se em dendritas primárias enriquecida por cromo e carbono, que posteriormente se transformou em carbonetos. Estas fases tendem a consumir grande parcela do teor de cromo e carbono, o que pode ter facilitado seu crescimento. Além disso, durante este processo, a matriz se torna pobre em cromo, porém ainda há formação de carbonetos do tipo $\mathrm{M}_{7} \mathrm{C}_{3}$ no processo de transfor- 
mação eutética. De acordo com OGI et al. [15], quanto maior teor de cromo, maior o tamanho dos carbonetos eutéticos formados e menor a uniformidade, resultando em uma microestrutura final (carbonetos primários grosseiros) que podem ou não estar agrupados, além de carbonetos refinados no entorno.

A Figura 4 apresenta a microestrutura da liga B, Fe-Cr-C $(25 \% \mathrm{Cr})$, que exibiu crescimento dendritico, e carbonetos primários, $\mathrm{M}_{7} \mathrm{C}_{3}$ proeutéticos, concentrados na matriz. Estas fases se apresentaram menos grosseiras em relação ao encontrado na liga A. Estes precipitados se encontram agrupadas de forma regular e refinados em uma mistura eutética, como encontrado por BUCHANAN et al. [5]. A distribuição dos carbonetos na matriz, também se apresentou diferente em relação à liga $\mathrm{A}$, pois além de estarem em colônias, se apresentaram separadas entre si por um grande espaçamento. A fase primária, dendrítica, pode ser observada com clareza, tal fato pode ser devido ao resfriamento da liga, pois ao ser sub-resfriada, permitiu maior taxa de crescimento das dendritas, inibindo a precipitação de carbonetos secundários [17], como ocorreu na liga $\mathrm{A}$.

A microestrutura da liga $\mathrm{C}, \mathrm{Fe}-\mathrm{Cr}-\mathrm{C}-\mathrm{Nb}$, pode ser observada na Figura 5. Assemelha-se à microestrutura da liga $\mathrm{B}$, em relação ao crescimento dendrítico. No entanto, além de carbonetos do tipo $\mathrm{M}_{7} \mathrm{C}_{3}$, estas ligas apresentam carbonetos de nióbio $(\mathrm{NbC})$. Para esta composição, esta fase exibiu formas alongadas, denominada "escrita chinesa", que se formaram de modo intercalado aos carbonetos de cromo presentes. Esta morfologia do NbC, segundo CASTELO BRANCO et al. [17] e ADNANE E KESRI [18], é típica dos eutéticos de nióbio, pois sua formação se dá a partir do líquido e, geralmente, não há interferência nos processos de solidificação, bem como reações do estado sólido. Os carbonetos do tipo $\mathrm{M}_{7} \mathrm{C}_{3}$ presentes, se encontram distribuídos entre as dendritas, dispostos em colônias e com morfologia refinada, em comparação às outras duas ligas, o que se deve à presença de nióbio, que por apresentar maior afinidade ao carbono pode ter causado uma redução no intervalo de solidificação da liga, diminuindo o tempo de difusão do carbono e crescimento dos carbonetos [19].

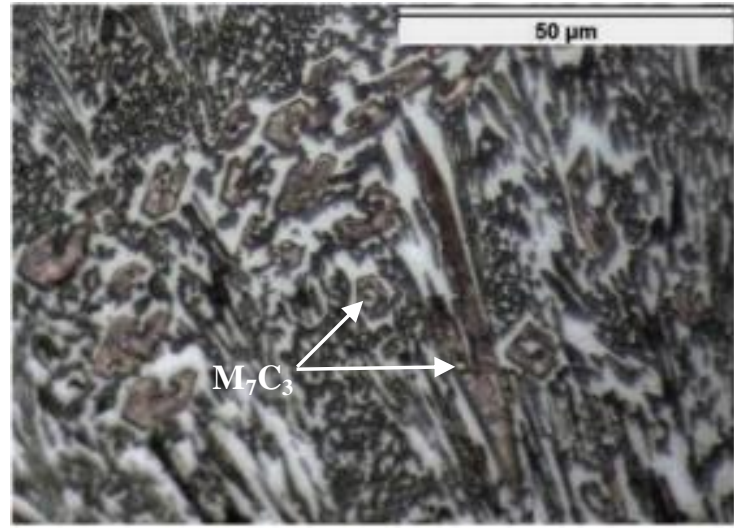

(a)

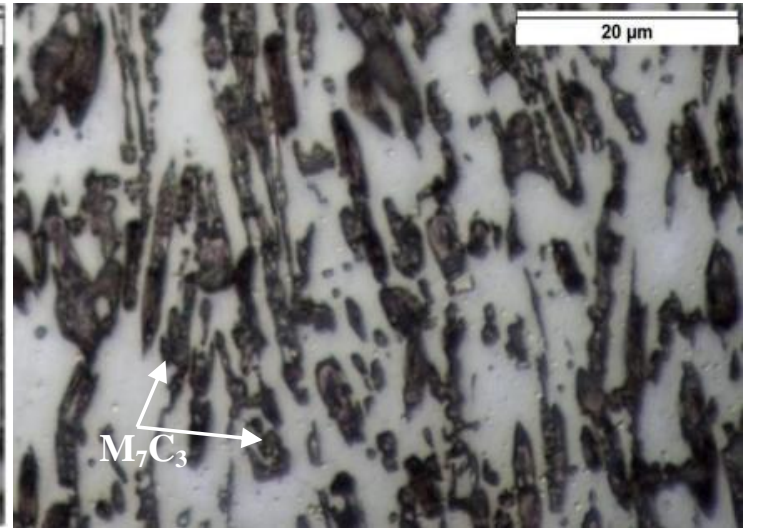

(b)

Figura 3: Microestrutura na superfície do revestimento A. (a) 500x e (b) 1000x. (ataque Murakami a 60º (MO).

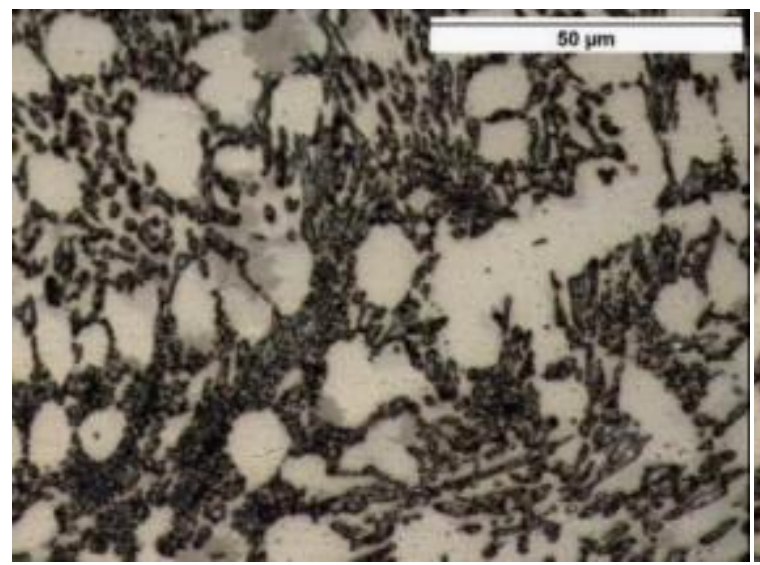

(a)

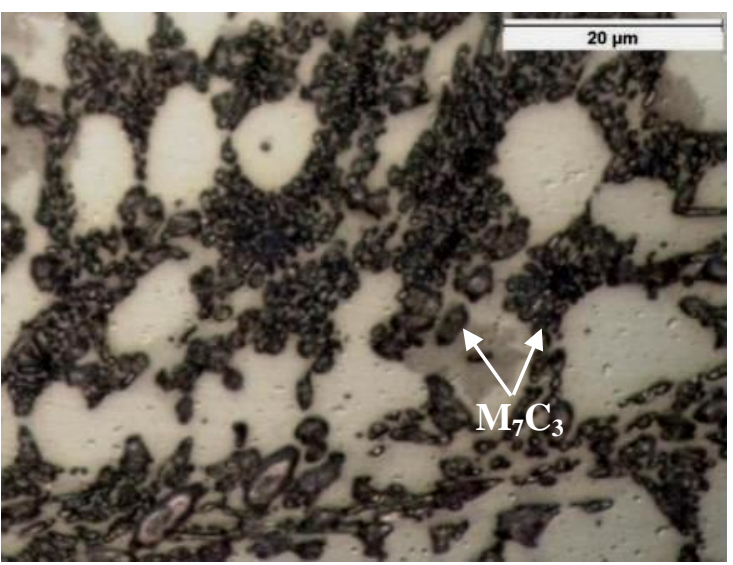

(b)

Figura 4: Microestrutura na superfície do revestimento B. (a) 500x e (b) 1000x. (ataque Murakami a 60º $(\mathrm{MO})$. 


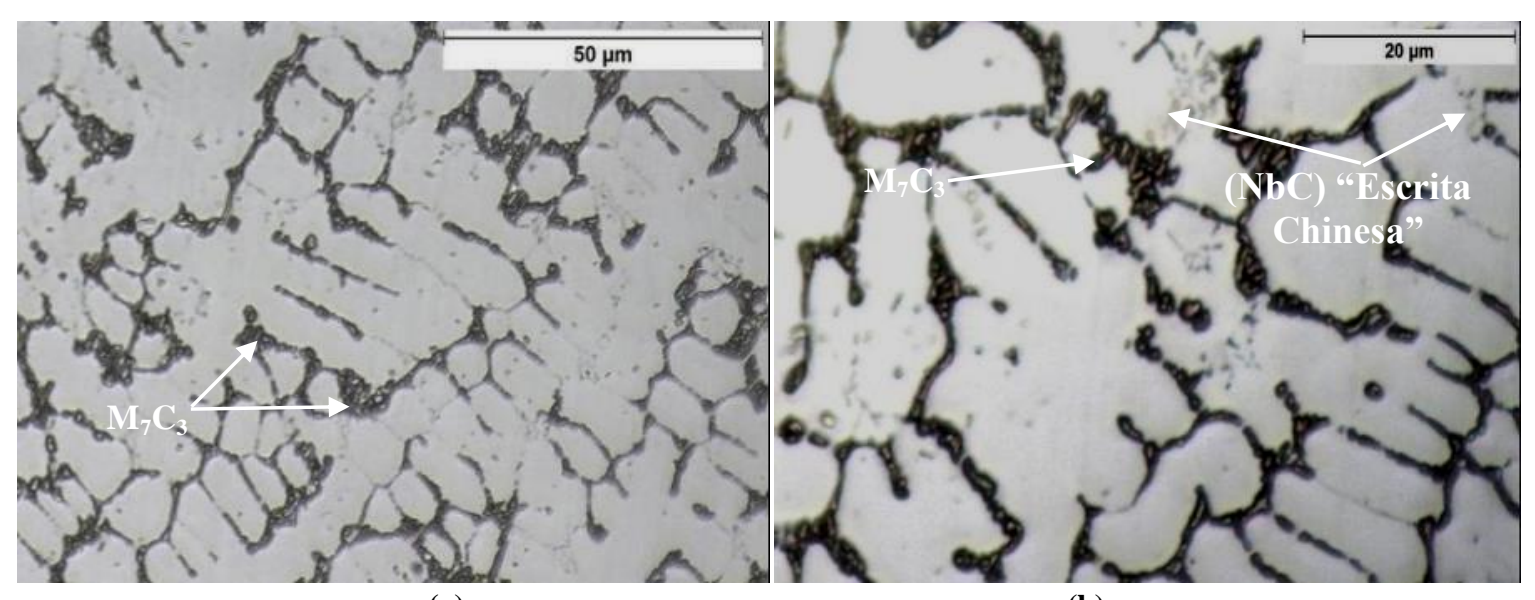

(a)

(b)

Figura 5: Microestrutura na superfície do revestimento C. (a) 500x e (b) 1000x. (ataque Murakami a 60º (MO).

Em busca de comprovação da presença de precipitados nas ligas estudadas foi obtida a composição química das fases presentes na microestrutura. As imagens obtidas pelo MEV das microestruturas e os espectros pontuais realizados por EDS para as ligas A, B e C, são mostrados nas Figuras 6, 7 e 8, respectivamente.

A Figura 6(b) revela a análise de composição química, via EDS, da região indicada pela seta correspondente na Figura 6(a). Pode-se observar a presença dos elementos cromo e carbono com teores $34,8 \%$ e $13,8 \%$, respectivamente, os quais compõem a estrutura de carbonetos, que podem corresponder ao tipo $\mathrm{M}_{7} \mathrm{C}_{3}[15]$.

Para a liga B, Figura 7(b), em que a análise de EDS foi realizada na região indicada na Figura 7(a), pôde-se constatar a presença dos precipitados de composição química semelhante ao encontrado para a liga A.

A Figura 8(b) apresenta os espectros pontuais realizados a partir do EDS para a liga C, correspondente ao indicado na Figura 8(a). Esta análise mostra que os constituintes analisados são formados basicamente pelos elementos nióbio e cromo, ou seja, provavelmente estão formando junto ao carbono os carbonetos do tipo $\mathrm{NbC}$ e $\mathrm{M}_{7} \mathrm{C}_{3}$, respectivamente.

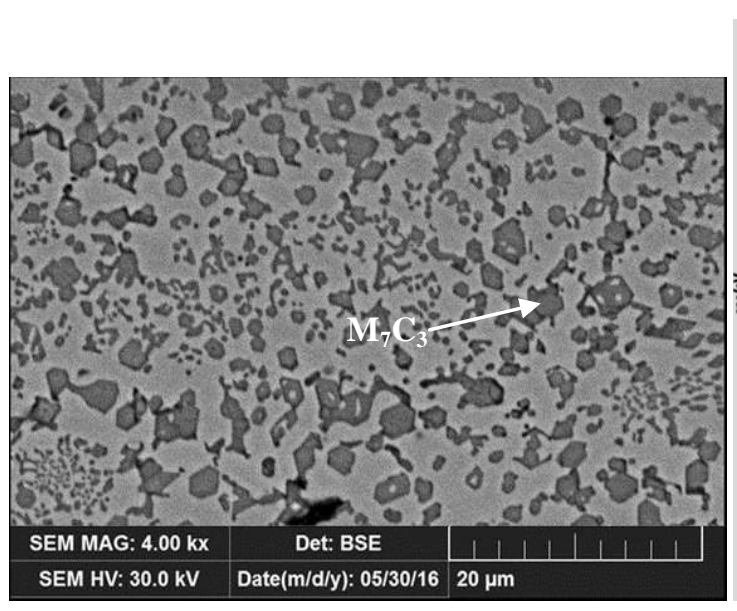

(a)

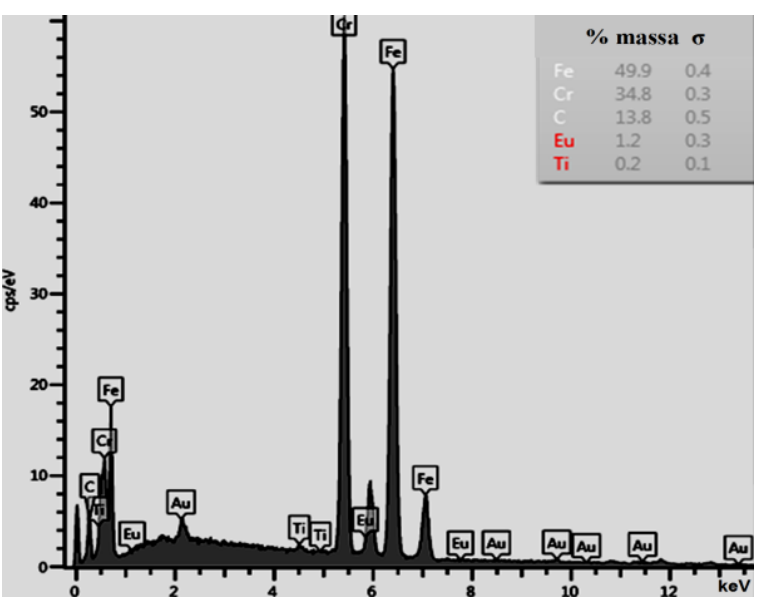

(b)

Figura 6: Microestrutura do revestimento obtido a partir da liga A. (aumento de 4000x). Espectro de EDS da microestrutura. 


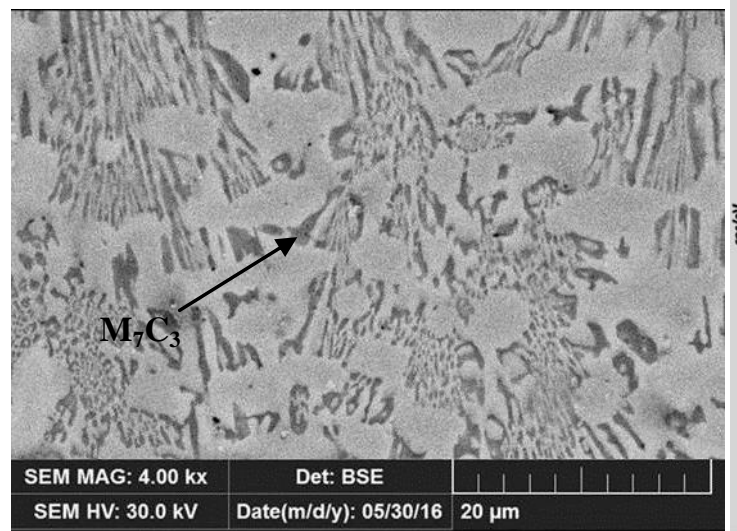

(a)

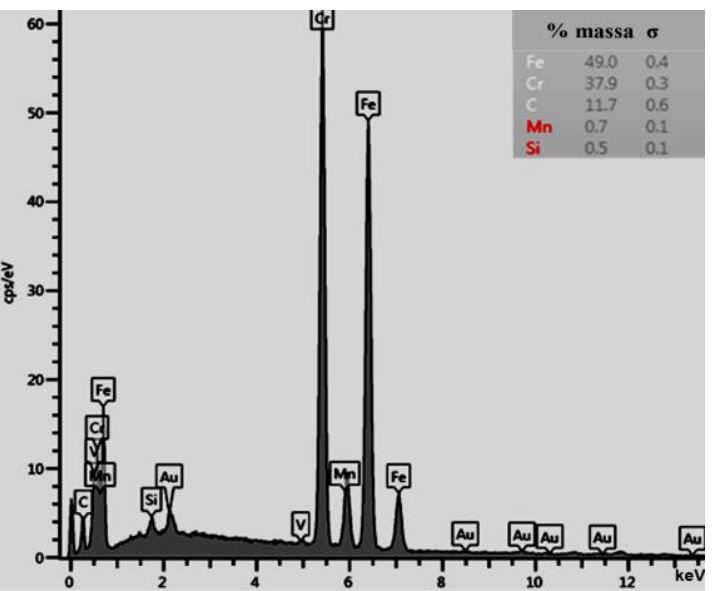

(b)

Figura 7: Microestrutura do revestimento obtido a partir da liga B. (aumento de 4000x). Espectro de EDS da microestrutura.

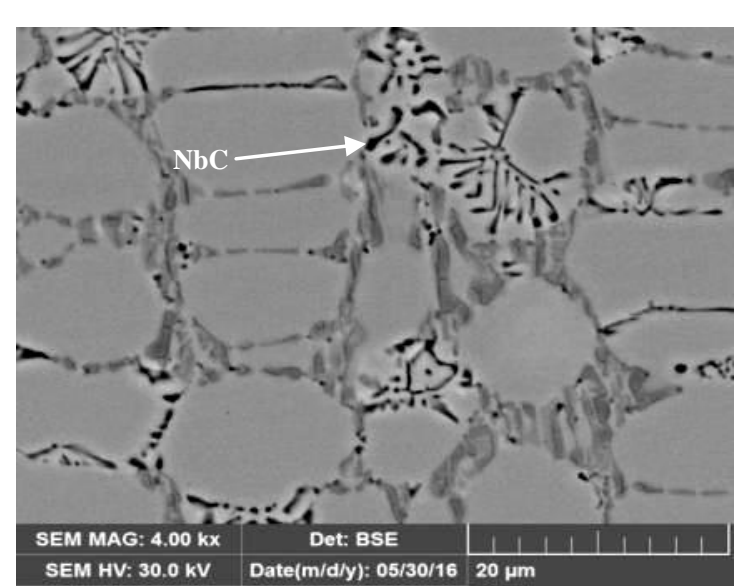

(a)

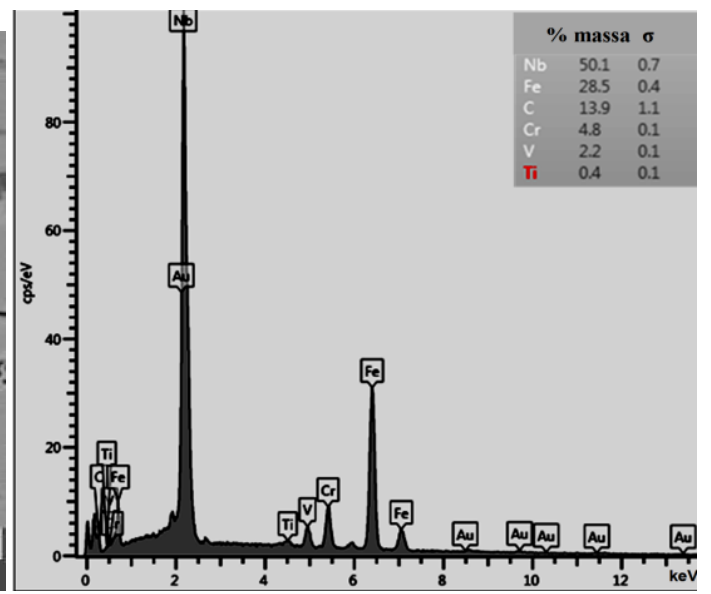

(b)

Figura 8: Microestrutura do revestimento obtido a partir da liga C. (aumento de 4000x). Espectro de EDS da microestrutura.

O percentual de carbonetos foi obtido utilizando o programa "ImageJ". Como resultado obtivemos o maior percentual de carbonetos para a liga A, seguida pela liga B e por fim a liga C. A Figura 9 apresenta o percentual de carbonetos obtido a partir da medição em 10 áreas para cada revestimento estudado e seus respectivos desvios padrão.

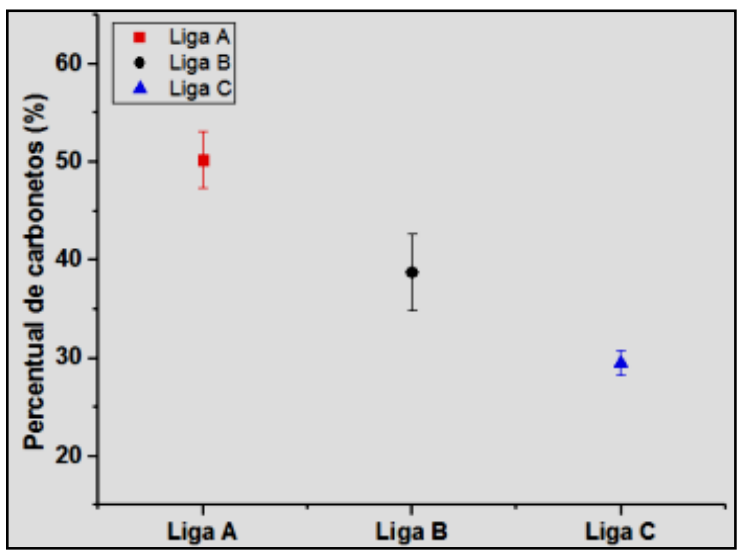

Figura 9: Percentual de carbonetos para as ligas A, B e C. 


\subsection{Análises de desgaste por microabrasão}

$\mathrm{O}$ estudo do desgaste microabrasivo se baseou em ensaios que permitiram quantificar o volume desgastado dos corpos de prova. Inicialmente foi obtida a evolução do diâmetro das crateras formadas em função da distância de deslizamento, conforme ilustrado na Figura 10. Para esta análise, utilizou-se a distância de $651 \mathrm{~m}$, ou seja, 60 minutos de ensaio, a partir da qual as três ligas apresentaram coeficiente de desgaste constante e, portanto considera-se que o regime permanente de desgaste foi atingido [20]. A liga $\mathrm{C}$, foi a que apresentou menores dimensões das calotas, seguida pela liga A e por fim a liga B.

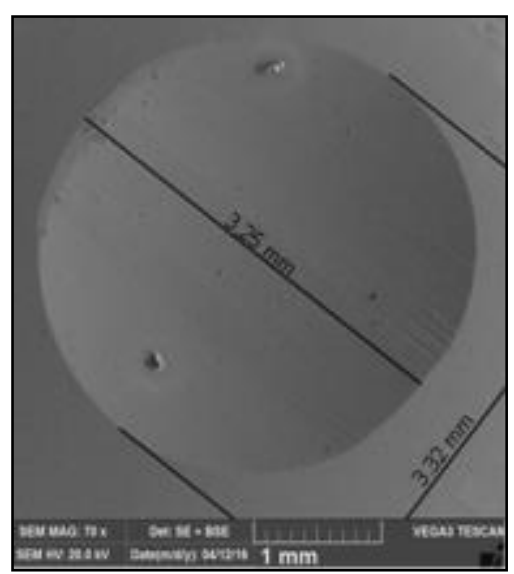

(a)

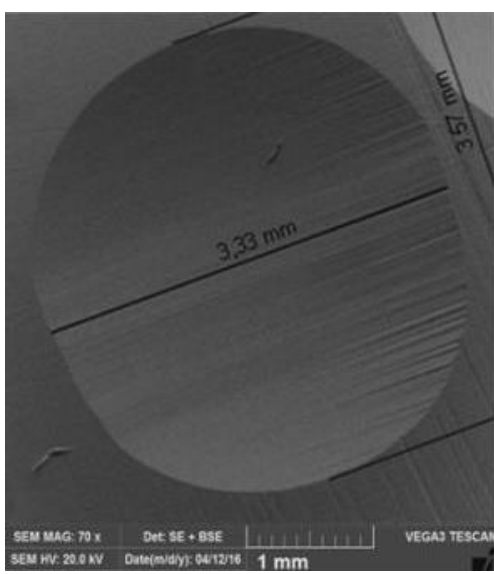

(b)

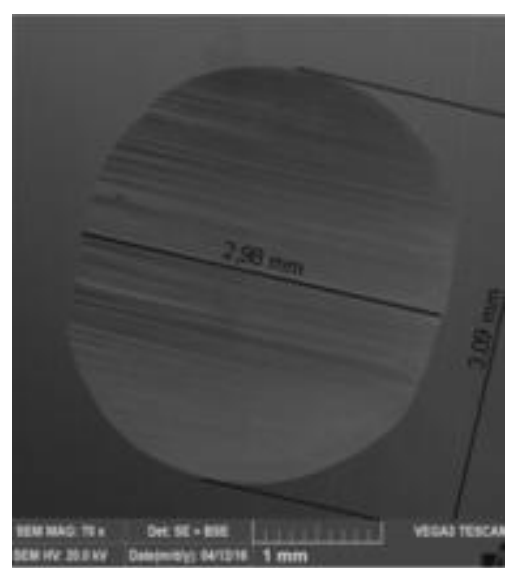

(c)

Figura 10: Calotas obtidas para os revestimentos A (a), B (b) e C (c), em função da distância de deslizamento.

Os gráficos das Figuras 11 (a) e (b) representam, respectivamente, o volume desgastado (V) e coeficiente de desgaste $(\mathrm{k})$ em função da distância de deslizamento. O revestimento $\mathrm{C}, \mathrm{Fe}-\mathrm{Cr}-\mathrm{C}(5 \% \mathrm{Nb})$, apresentou menor volume desgastado total e menor coeficiente de desgaste, apesar de ter apresentado menor valor de dureza em relação aos outras duas ligas. O que condiz com KOTECKI et al. [22] e LEMM et al. [23], que defendem que a dureza não deve ser considerada, isoladamente, como um indicador da resistência ao desgaste.
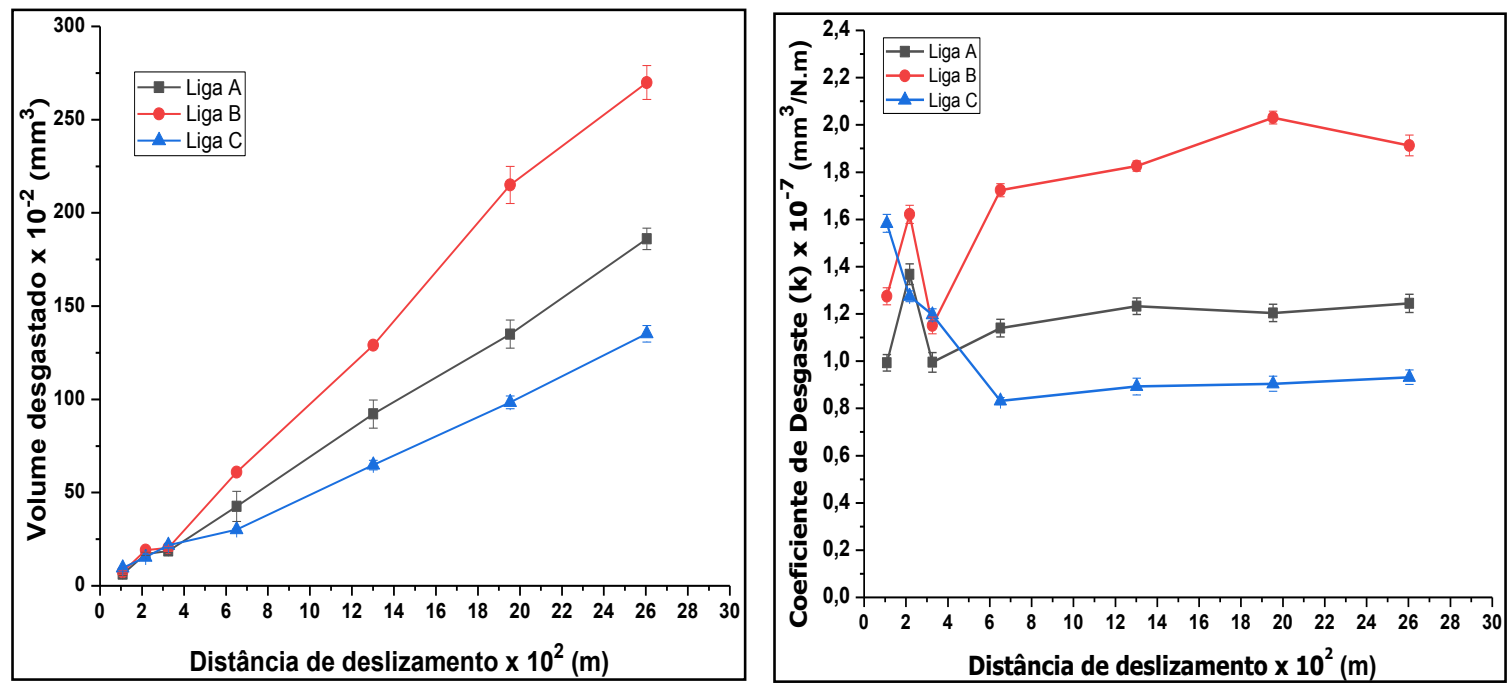

Figura 11: Resultado do ensaio de desgaste das ligas A, B e C em função da distância de deslizamento. (a) Volume total desgastado e (b) comportamento do coeficiente de desgaste (k). 
O gráfico da Figura 12 mostra o comportamento do volume desgastado em função do percentual de carbonetos. Pode-se observar que a liga $\mathrm{C}$, apresentou menor percentual de carbonetos, no entanto foi o revestimento com melhor resistência ao desgaste. Ao se comparar as duas ligas livres de nióbio, A e B, o revestimento A, exibiu maior percentual de carbonetos e menor volume desgastado em relação à B. Este resultado pode estar relacionado à maior proteção dada à matriz pelos carbonetos presentes em $\mathrm{A}$, pois a liga $\mathrm{B}$, exibiu uma distribuição com maior caminho livre para as partículas de abrasivo penetrarem e arrancarem parte do material da matriz. [8, 24, 25]. Além disso, a presença de carbonetos primários em matriz eutética, na liga A, proporcionaram melhor resistência ao desgaste em relação aos constituintes eutéticos e austenita, presentes na liga $\mathrm{B}[26,27]$.

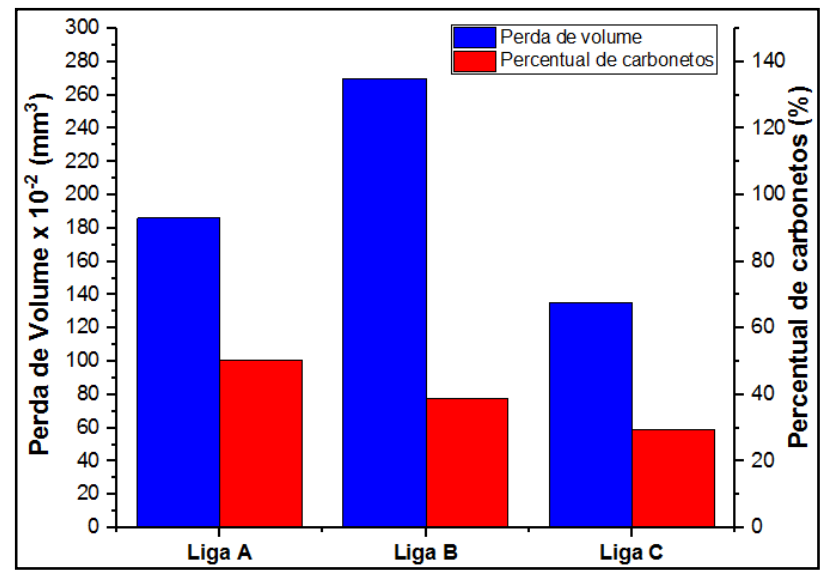

Figura 12: Efeito do percentual de carbonetos na perda de volume dos revestimentos das ligas A, B e C.

Os mecanismos de desgastes apresentados pelas ligas A, B e C podem ser analisados a partir da Figura 13, obtidas com o auxilio do MEV com um aumento de 2000x. Verifica-se que para as três ligas as marcas de desgaste se apresentam semelhantes, em forma de linhas paralelas e bem definidas, o que indica a ocorrência de microriscamento [28].

Ao observarmos a Figura 13(b) e (c), referentes às ligas B e C, respectivamente, percebe-se que não há indícios de que os riscos presentes tenham sido interrompidos durante seu curso, o que pode estar relacionado ao maior refinamento dos carbonetos presentes. De acordo com [29] carbonetos grosseiros tendem a barrar os riscos e provocar arrancamentos. Para a liga A, houve algumas ocorrências em que os riscos foram barrados, além de apresentar detritos que podem ter sido gerados devido ao corte dos carbonetos presentes.

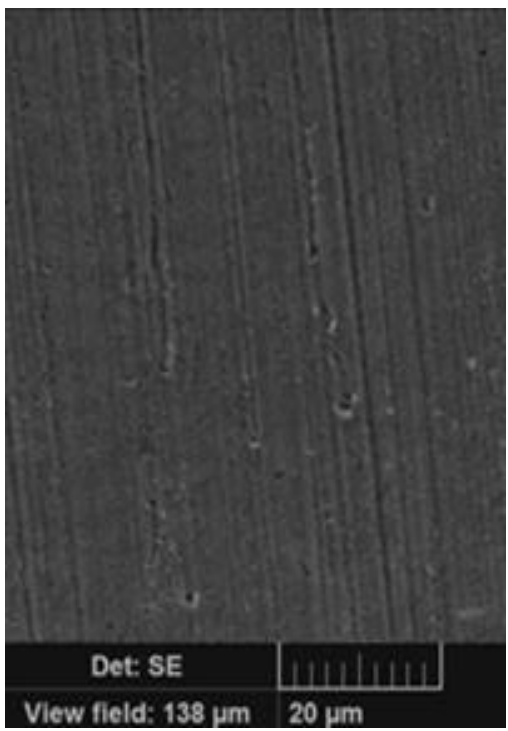

(a)

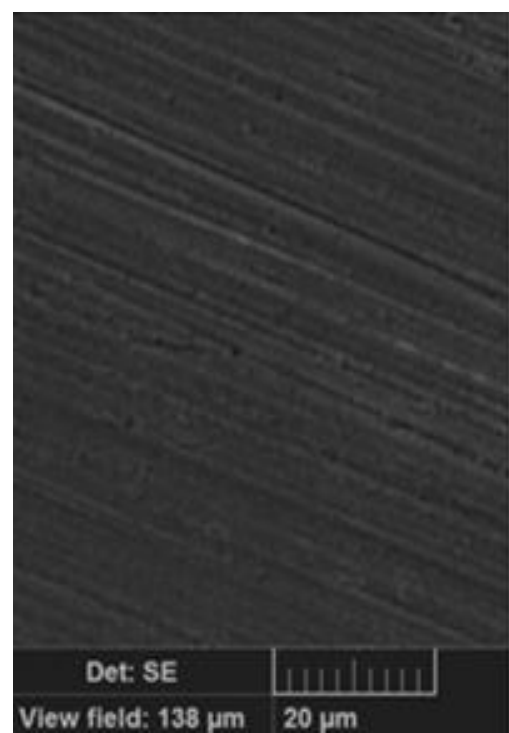

(b)

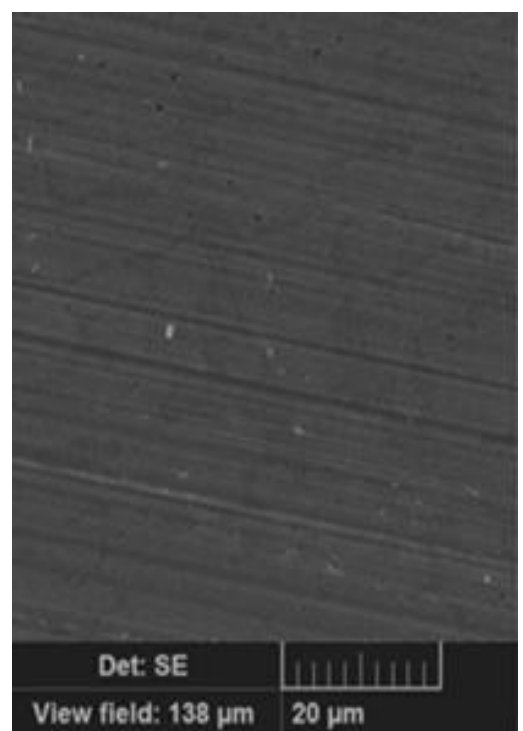

(c)

Figura 13: Mecanismo de desgaste apresentado pelas ligas estudadas. (a) liga A, (b) liga B e (c) liga C. 
A melhor resistência exibida pela liga $\mathrm{C}$, mesmo apresentando o menor percentual de carbonetos, pode estar relacionada às características apresentadas por essas fases, como a forma, o tamanho e a aderência dos carbonetos à matriz [30]. Acredita-se que o maior refinamento dos carbonetos presentes na liga $\mathrm{C}$, tenha dificultado seu arrancamento da matriz [29]. Além disso, os carbonetos ( $\mathrm{NbC}$ ) incrustados na matriz, contribui para uma maior proteção e, portanto maior resistência ao desgaste [31]. Outro fato é a forma mais preferencial para formação de carbonetos do nióbio em relação ao cromo, o que pode ter produzido uma matriz mais rica em cromo, provavelmente mais resistente em relação às outras ligas [32][33]. Segundo ZUM GHAR [30] e HUTCHINGS [21], matrizes menos resistente tende a diminuir o suporte mecânico dos carbonetos, o que póde deixa-los mais vulneráveis ao desgaste. Em contrapartida, os carbonetos de cromo $\left(\mathrm{M}_{7} \mathrm{C}_{3}\right)$, presentes nas ligas $\mathrm{A}$ e $\mathrm{B}$, por se apresentarem mais grosseiros em relação à liga $\mathrm{C}$, tendem a se fraturar mais facilmente, além de aumentar a probabilidade de serem arrancados da matriz [29].

Os resultados encontrados confirmam que a morfologia e tamanho dos carbonetos podem ser fundamentais para a resistência ao desgaste. [30][32][33] E que o percentual de carbonetos influencia a resistência à abrasão, desde que os carbonetos analisados apresentem características similares.

\section{CONCLUSÕES}

Ao analisar os resultados obtidos neste estudo, pode-se concluir que no processo de seleção de materiais resistentes ao desgaste, devem ser avaliados outros parâmetros além da dureza. Pois a liga $\mathrm{C}, \mathrm{Fe}-\mathrm{Cr}-\mathrm{C}(5 \% \mathrm{Nb})$, apresentou o menor valor de dureza, porém a melhor resistência ao desgaste em relação às ligas $\mathrm{A}, \mathrm{Fe}-\mathrm{Cr}-\mathrm{C}$ $(45 \% \mathrm{Cr})$ e B, Fe-Cr-C (25\%Cr).

O percentual de carbonetos é um fator importante na análise de resistência ao desgaste, no entanto deve ser avaliado juntamente às características morfológicas e dimensionais destas partículas. Pois a liga $\mathrm{A}$ apresentou o maior percentual de carbonetos, seguido pela liga B e C. Porém, a resistência ao desgaste da liga $\mathrm{A}$ foi inferior ao apresentado pela liga $\mathrm{C}$, devido aos carbonetos existentes em A se apresentarem de forma mais grosseira, o que pode ter facilitado o arrancamento ou fratura destas partículas.

Para ligas de mesma família, que apresentem carbonetos com características similares, o percentual de carbonetos influencia diretamente na resistência ao desgaste. Neste caso, ao comparar os resultados obtidos pelas ligas A e B, o menor volume desgastado foi exibido pela liga A, que também apresentou maior percentual de carbonetos.

A presença de nióbio no revestimento $C$ contribuiu para a maior resistência a abrasão, devido a presença de carbonetos de nióbio ( $\mathrm{NbC}$ ), que apresentaram forte aderência, dificultando o arrancamento dos mesmos durante o processo de desgaste. Além disso, o nióbio, por apresentar maior afinidade pelo carbono, pode ter contribuído para formação de uma matriz mais rica em cromo e, portanto mais resistente ao desgaste.

\section{AGRADECIMENTOS}

Os autores agradecem o suporte da UFOP, FAPEMIG, Fundação Gorceix e NanoLab.

\section{BIBLIOGRAFIA}

[1] LEITE, R. V. M., MARQUES, P. V., "Comparative study of the wear resistance of three metal cored wire welded coatings used in industry”, Soldagem \& Inspeção, v. 14, n. 4, pp. 329-335, 2009.

[2] KIRCHGAßNER, M., BADISCH, E., FRANEK, F., "Behaviour of iron-based hardfacing alloys under abrasion and impact”, Wear, v. 265, n. 5, pp. 772-779, 2008.

[3] CORONADO, J.J., CAICEDO, H.F., GOMEZ, A.L., "The effects of welding processes on abrasive wear resistance for hardfacing deposits”, Tribology International, v. 42, n. 5, pp. 745-749, 2009.

[4] BUCHELY, M. F., GUTIERREZ, J. C., LEÓN, L. M. "“The effect of microstructure on abrasive wear of hardfacing alloys", Wear, v. 259, n. 1, pp. 52-61, 2005.

[5] BUCHANAN, V. E., SHIPWAY, P. H., MCCARTNEY, D. G., "Microstructure and abrasive wear behaviour of shielded metal arc welding hardfacings used in the sugarcane industry", Wear, v. 263, n.1, pp. 99$110,2007$. 
[6] CORONADO, J.J., "Effect of $(\mathrm{Fe}, \mathrm{Cr})_{7} \mathrm{C}_{3}$ carbide orientation on abrasion wear resistance and fracture toughness", Wear, v. 270, n. 3, pp. 287-293, 2011.

[7] BENS, H., "Microstructural properties of wear-resistant alloys”, Wear, v. 181, pp. 271-279, 1995.

[8] CORRÊA, E. O., Avaliação da resistência ao desgaste de ligas desenvolvida para solda de revestimento duro para uso sob condições altamente abrasivas, Tese de D.Sc., Universidade Federal de São Carlos, São Carlos-SP, Brasil, 2005.

[9] LIMA, A. C., Estudo da aplicação de revestimento duro por soldagem com arames tubulares quanto à resistência ao desgaste de facas picadoras de cana-de-açúcar, Tese D.Sc., Universidade Federal de Uberlândia, Uberlândia-MG, Brasil, 2008.

[10] PRETI, O., Seleção de inoculantes para refino de liga hipereutética de ferro branco de alto cromo, Tese D.Sc., Universidade Federal de Santa Catarina, Florianópolis-SC, Brasil, 2014.

[11] COZZA, R. C., "Influence of the normal force, abrasive slurry concentration and abrasive wear modes on the coefficient of friction in ball-cratering wear tests", Tribology International, v. 70, pp. 52-62, 2014.

[12] ISO 26424 -2015, Fine ceramics (advanced ceramics, advanced technical ceramics) - Determination of the abrasion resistance of coatings by a micro-scale abrasion test, 2015.

[13] GARCÍA, D.B.C., Aplicação de revestimento duro utilizando o processo de arame tubular com e sem adição de arame não energizado para diferentes tipos de consumíveis, Dissertação M.Sc., Universidade Federal de Uberlândia, Uberlândia-MG, Brasil, 2011.

[14] WU, X., XING, J., FU, H., et al., "Effect of titanium on the morphology of primary $\mathrm{M}_{7} \mathrm{C}_{3}$ carbides in hypereutectic high chromium white iron", Materials Science and Engineering: A, v. 457, n. 1, pp. 180-185, 2007.

[15] OGI, K., MATSUBARA, Y., MATSUDA, K., "Eutectic solidification of high-chromium cast ironmechanism of eutectic growth", American Foundrymen's Society, Transactions, v. 89, pp. 197-204, 1981.

[16] LU, L., SODA, H., MCLEAN, A.,"Microstructure and mechanical properties of Fe-Cr-C eutectic composites", Materials Science and Engineering A, v. 347, pp. 214-222, 2003.

[17] CASTELLO BRANCO, C. H., BECKERT, E. A., "Niobium in gray cast iron", Companhia Brasileira de Metalurgia e Mineracão, 1984.

[18] ADNANE, L., KESRI, R., HAMAR-THIBAULT, S., "Vanadium carbides formed from the melt by solidification in Fe-V-X-C alloys (X-Cr, Mo, Nb)", Journal of alloys and compounds, v. 178, n. 1-2, pp. 7184, 1992.

[19] CHOTĚBORSKÝ, R., HRABĚ, P., MÜLlER, M., et al., "Abrasive wear of high chromium Fe-Cr-C hardfacing alloys", Research in Agricultural Engineering, v. 54, n. 4, pp. 192-198, 2008.

[20] COZZA, R. C., Estudo do desgaste e atrito em ensaios micro-abrasivos por esfera rotativa fixa em condições de força normal constante e pressão constante, Tese D.Sc., Universidade de são Paulo, São Paulo-SP, Brasil, 2011.

[21] HUTCHINGS, I. M., Tribology: friction and wear of engineering materials, Edward Arnold, London, pp.51, 1992.

[22] KOTECKI, D. J., OGBORN, J. S., “Abrasion resistance of iron based hardfacing alloy”, Welding Journal, v. 77, n. 1, pp. 269-278, 1998.

[23] LEMM, J. D., WARMUTH, A.R., PEARSON, S.R., et al., "The influence of surface hardness on the fretting wear of steel pairs - Its role in debris retention in the contact", Tribology International, v.81, pp. 258$266,2015$.

[24] WANG, Q. B., LI, X. Y., "Effects of Nb, V, and W on microstructure and abrasion resistance of Fe-CrC hardfacing alloys", Weld, v. 89, n. 7, pp. 133-139, 2010.

[25] RIBEIRO, R., Avaliação da Resistência ao Desgaste Abrasivo de Revestimentos Soldados do Tipo FeC-Cr Utilizados na Indústria Sucroalcooleira, Dissertação M.Sc., Faculdade de Engenharia de Ilha Solteira, UNESP, Ilha Solteira-SP, Brasil, 2004.

[26] ATAMERT, S., BHADESHIA, H. K. D. H., "Microstructure and stability of Fe-Cr-C hardfacing alloys", Materials Science and Engineering, A, v. 130, n. 1, pp. 101-111, 1990.

[27] SEVILLA, L. M. L., PINEDA, J. C. G., TORO, A., "Relación microestructura resistencia al desgaste de recubrimientos duros ricos en cromo y tungsteno aplicados por soldadura electrica (SMAW)", Dyna, v. 71, n. 144, pp. 165-171, 2004. 
[28] COZZA, R. C., Estudo do comportamento do coeficiente de desgaste e dos modos de desgaste abrasivo em ensaios de desgaste micro-abrasivo, Dissertação M. Sc., Escola Politécnica, Universidade de São Paulo, São Paulo, Brasil, 2006.

[29] ALBERTIN, E., SINATORA, A., "Effect of carbide fraction and matrix microstructure on the wear of cast iron balls tested in a laboratory ball mill", Wear, v. 250, pp. 492-501, 2001.

[30] ZUM GAHR, K. H., Microstructure and wear of material, Institute of Materials Technology, University of Siegen -Germany, Elsevier, 560p, 1987.

[31] REGATTIERI, C. N. B., Estudo da Resistência ao Desgaste Abrasivo de Ferros Fundidos Brancos Alto Cromo e Molibdênio, Dissertação M.Sc., Universidade Federal do espírito Santo, Vitória-Es, Brasil, 2006.

[32] FILIPOVIC, M., KAMBEROVIC, Z., KORAC, M., GAVRILOVSKI, M., "Microstructure and mechanical properties of Fe-Cr-C-Nb white cast irons", Materials and Design, v. 48, pp. 41-48, 2013.

[33] ZHI, X., XING, J., FU, H., XIAO, B., "Effect of niobium on the as-cast microstructure of hypereutectic high chromium cast iron”, Materials Letters, v. 62, pp. 857-860, 2008.

\section{ORCID}

Tatiane Gabi Oliveira https://orcid.org/0000-0001-7290-869X

Adilson Rodrigues da Costa https://orcid.org/0000-0002-3123-0701 